\title{
"É LAZER, TUDO BEM, MAS É SÉRIO": NOTAS SOBRE LAZER A PARTIR DO COTIDIANO DE UMA EQUIPE MÁSTER FEMININA DE VOLEIBOL
}

\author{
"IT'S LEISURE, ALRIGHT, BUT IT'S SERIOUS": NOTES ON LEISURE FROM \\ THE DAILY LIFE OF A MASTER LEAGUE WOMEN'S VOLLEYBALL TEAM
}

"ES OCIO, ESTÁ BIEN, PERO ES EN SERIO": NOTAS SOBRE EL OCIO A PARTIR DEL COTIDIANO DE UN EQUIPO MÁSTER FEMENINO DE VOLEIBOL

\author{
Ariane Corrêa Pacheco*, Marco Paulo Stigger*
}

\section{Palavras-chave}

Lazer.

Esportes.

Mulheres.

Etnografia.

Keywords

Leisure.

Sports.

Women.

Ethnography.

Palabras clave

Ocio.

Deportes.

Mujeres.

Etnografía.

\begin{abstract}
Resumo: Este trabalho traz elementos para discussões sobre o lazer (enquanto lócus e objeto) que emergem de uma etnografia com um grupo de mulheres. $O$ objetivo foi compreender como uma equipe se sustentava e se mantinha engajada à Liga Máster Feminina de Voleibol de Porto Alegre/RS. Inicialmente, discutimos sobre a noção de tempo e uma lógica de obrigações que colocam o lazer em oposição a outras dimensões do cotidiano. Após, debatemos sobre "atitudes" que assumem adjetivações ligadas à seriedade. Percebemos que as negociações cotidianas borravam fronteiras entre dimensões e, além disso, colocavam aquele lazer como um espaço/tempo "levado a sério".
\end{abstract}

Abstract: This paper provides elements for discussions on leisure (both as locus and object) resulting from an ethnographic work conducted with a group of women. It aimed at understanding how their team was sustained and remained committed to the Women's Volleyball Master League in Porto Alegre, RS, Brazil. Firstly, we discuss the notion of time and the obligation-based logic that opposes leisure to other dimensions of daily life. Afterwards, we debate "attitudes" that take on adjectives related to seriousness. We found that daily negotiations blurred boundaries between dimensions and also placed that leisure as space/time "taken seriously".

Resumen: Este trabajo trae elementos para discusiones sobre el ocio (en tanto locus y objeto) que emergen de una etnografía con un equipo de mujeres, cuyo objetivo fue comprender cómo ese equipo se sostenía y se mantenía vinculado a la Liga Máster Femenina de Voleibol de Porto Alegre/RS. Inicialmente, discutimos sobre la noción de tiempo y una lógica de obligaciones que coloca al ocio en oposición a otras dimensiones del cotidiano. Después, discutimos sobre 'actitudes' que asumen adjetivaciones ligadas a la seriedad. Percibimos que las negociaciones cotidianas borraban fronteras entre dimensiones y, además, colocaban ese ocio como un espacio/tiempo 'tomado en serio'.
* Universidade Federal do Rio Grande do Sul. Porto Alegre, RS, Brasil. E-mail: arianepacheco@gmail.com

Recebido em: 08-12-2014 Aprovado em: 05-06-2015 (c) (1) () L) Licence 


\section{INTRODUÇÃO}

Pensar "no lazer" enquanto lócus de um estudo ou "o lazer" como um objeto de análise poderia conduzir a diferentes formas de construir uma pesquisa e, sendo ainda mais particular, poderíamos delimitar maneiras de olhar para cotidianos. Foi essa polarização que pautou o início de uma pesquisa etnográfica junto a uma equipe máster feminina de voleibol da cidade de Porto Alegre/RS. Durante o trabalho, e nas inúmeras reflexões que ainda emergem dele, as definições "de lazer" foram extrapolando contornos a partir "do lazer" daquelas mulheres, desmanchando categorias e nos fazendo problematizar noções sobre tempos, espaços e atitudes.

Partindo da ideia de que a etnografia está ligada a uma "ciência, por excelência, do concreto" (FONSECA, 1999, p.59), passamos a observar aquela equipe e o contexto da Liga, principalmente, sob a influência de uma tradição de estudos antropológicos que se basearam em densos trabalhos de campo. A solidez de autores como Geertz (1989), Foote-White (1980), Winkin (1998), Cardoso de Oliveira (2006), além de outras etnografias que seguiram uma linha interpretativa, especialmente aquelas relacionadas ao esporte, como o trabalho de Stigger (2002) e as produções do Grupo de Estudos Socioculturais em Educação Física (GESEF/ UFRGS), foram basilares neste exercício de tentar "ler por sobre os ombros" (GEERTZ, 1989, p.321) daquele grupo de mulheres.

Sistematicamente, durante 13 meses de trabalho de campo, acompanhamos uma equipe que passamos a chamar de Moinhos ${ }^{1}$. Foi no decorrer das observações, sempre participantes e acompanhadas dos registros em diários de campo, que conseguimos perceber que este grupo era formado por um número aproximado ${ }^{2}$ de 15 mulheres, com idades entre 32 e 65 anos. Essa definição etária estava diretamente relacionada com a participação do grupo na Liga Máster Feminina de Voleibol, uma organização independente que se articulava em função de 12 equipes da capital gaúcha, da Região Metropolitana, Lajeado e Caxias do Sul.

Mesmo que inserida na dimensão do lazer das participantes, dentre os requisitos para que as mulheres pudessem pertencer à Liga, estavam: o compromisso de participar das etapas de jogos que aconteciam no último sábado de cada mês (março a dezembro); o pagamento de taxas de inscrição e arbitragem; a disponibilidade em negociar o "seu" tempo para as competições e jogos amistosos. Cabe destacar que esses eram "esforços" que faziam parte de permanecer em um campeonato máster reconhecido como de "alto nível" pelas pessoas que circulavam naquele contexto esportivo.

A equipe Moinhos mantinha alguns compromissos em sua agenda diária, alguns "dentro de quadra" e outros relacionados com jantares, festas e comemorações. Os encontros que denominamos como parte de uma "rotina das quadras" estavam organizados em função dos treinamentos, campeonatos e jogos amistosos. Nesses momentos entravam em cena as negociações sobre o significado de cada elemento que pertencia ao voleibol e, particularmente, sobre o que se esperava de um "bom treino", um "bom treinador", uma "boa jogadora" e uma "boa partida".

A sustentação daquela formação de grupo também dependia dos eventos sociais, tais como jantares, festas e reuniões que não faziam parte apenas de uma lógica complementar

1 Utilizamos pseudônimos para as equipes e pessoas citadas no trabalho.

2 Não foi possível definir um número exato de participantes, pois durante a pesquisa encontramos certa rotatividade de algumas jogadoras entre as equipes da Liga, aconteceram lesões que afastaram determinadas pessoas e certas situações particulares determinaram outras ausências. 
"para além dos jogos", mas estavam embutidos na lógica cotidiana de cada uma daquelas mulheres.

Foi no desenrolar desta experiência e prática etnográfica33 (MAGNANI, 2009) que as discussões sobre o lazer se sobressaíram no próprio trabalho de campo. Essa definição dentro da pesquisa aconteceu especialmente a partir de uma situação presenciada em um dia de treinamento, na qual uma das mulheres da equipe, após uma conversa entre todo grupo, pareceu reafirmar uma demarcação ao dizer que o voleibol por elas praticado "é lazer, tudo bem, mas é sério" (DC $\left.{ }^{4}, 16 / 11 / 2010\right)$. Cabe destacar que isso ocorreu sem que ela recebesse qualquer contestação das outras integrantes do grupo.

Porém, se, para as mulheres que faziam parte da equipe Moinhos, parecia não soar nada "estranha" aquela afirmativa, para nós, ela não era algo "familiar". Naquele momento, fomos remetidos a determinadas concepções sobre lazer que levam a entender que a seriedade se coloca como uma contradição num espaço/tempo que até então parecia ser significado como local da liberdade, da ludicidade, da livre escolha e participação fruída ${ }^{5}$. Foi dessa maneira que a pesquisa de campo instigou a busca de uma discussão sobre o lazer como uma dimensão da vida daquelas mulheres que também era "levada a sério".

Em conjunto com essa situação específica da pesquisa, inicialmente caracterizada pela imersão "no lazer" de uma equipe de mulheres jogadoras de voleibol máster, encontramos uma problematização sobre "o lazer" e sobre suas conceituações. Dessa maneira, deixamos de estabelecer polarizações ou dialogar a partir delas, mas, sim, passamos a pensar sobre como as práticas cotidianas daquele grupo extrapolavam conceitos que oferecem delimitações entre tempos e espaços.

Por essa razão, nosso esforço de discussão estará centrado em construir reflexões a partir de trabalhos que já abordam tensões sobre a "seriedade" e que trazem pistas sobre compromissos, investimentos e dedicações que também estão entre as práticas cotidianas de "pessoas comuns"6 que se dedicam ao esporte no seu lazer. No primeiro tópico deste texto nos propomos - em diálogos com trabalhos empíricos - a discutir sobre as delimitações da noção de tempo e sobre uma lógica de obrigações que diferenciariam o lazer de outras esferas do cotidiano. No segundo eixo, a proposta será debater sobre as atitudes que assumem adjetivações diferentes daquelas ligadas às ideias de lúdico e de brincadeira, tensionadas por questões de habilidades, exigências e performances que eram necessárias para a sustentação daquele grupo de mulheres.

Nesse diálogo constante entre lócus e objeto, pretendemos seguir olhando para o lazer não como uma dimensão da vida "entre parênteses", mas como parte da complexidade da vida cotidiana (STIGGER, 2009). No decorrer da pesquisa e nas problematizações que continuam

\footnotetext{
3 As definições metodológicas desta pesquisa não estão acompanhadas somente de uma escolha por determinadas ferramentas (observação participante, diários de campo e entrevistas), mas, sobretudo, caracterizaram um esforço interpretativo e foram também alimentadas pelas noções de "prática etnográfica" e "experiência etnográfica" (MAGNANI, 2009, p. 136). A primeira se refere às estratégias de contato, registros, sistematizações, anotações, observações e tudo o que pode ser programado dentro de uma pesquisa e que está em diálogo com a imprevisibilidade da experiência de fazer uma etnografia, cujo contato com outras representações nos oferece a possibilidade de encontrar pistas não previstas anteriormente.

4 Diário de Campo.

5 Essas noções aparecem, com certa frequência, na bibliografia sobre lazer no contexto da Educação Física brasileira, tais como: Gaelzer (1979); Camargo (1989); Gomes (2004a); Marcellino (2008)

6 Ao falar em "pessoas comuns" estamos nos remetendo à noção que pautou o trabalho de Stigger (2002) ao estudar o esporte em situações particulares e sendo vivenciado pelas pessoas que estão distantes dos holofotes do alto rendimento, mas que escolhem inserir o esporte no seu dia a dia e, particularmente, em seus modos de vida.
} 
em pauta, escolhemos abordar o tema "com as pessoas", procurando o diálogo constante com as suas práticas e significações.

\section{LAZER PARA ALÉM DOS PARÊNTESES}

No Brasil, as marcas de um processo histórico dos estudos no campo do lazer alicerçam as suas definições em diferentes lógicas de oposição ${ }^{7}$, as quais ainda permanecem em evidência. Seguindo na esteira desses debates, pensaríamos o lazer em contraposição às "obrigações com o trabalho", como um tempo distinto daqueles que envolvem as "obrigações familiares" e, além disso, pautado por uma diversa gama de classificações que acabam colocando-o como uma dimensão da vida entre parênteses.

Essas polarizações entre o lazer e "obrigações com o trabalho" foram basilares na proposta de Dumazedier $(1976)^{8}$, autor que influenciou não somente na constituição de um campo de estudos no Brasil, como continua a mostrar-se presente nos trabalhos que têm o lazer como tema e/ou lócus de estudo. Em seus trabalhos, sustentados em uma pesquisa com operários da indústria fabril, Dumazedier (1976) definiu o lazer como:

Um conjunto de ocupações às quais o indivíduo pode entregar-se de livre vontade, seja para repousar, seja para divertir-se, recrear-se e entreter-se ou, ainda para desenvolver sua informação ou formação desinteressada, sua participação social voluntária ou sua livre capacidade criadora após livrar-se ou desembaraçar-se das obrigações profissionais, familiares e sociais (DUMAZEDIER, 1976, p. 34).

De acordo com essa concepção, o lazer estaria envolto por uma lógica que vai de encontro às obrigações do cotidiano, especialmente quando relacionado ao trabalho, à família e às obrigações sociais. Além disso, o autor identificou que o lazer teria três funções principais: "a) função de descanso; b) função de divertimento, recreação e entretenimento; c) função de desenvolvimento" (DUMAZEDIER, 1976, p.32).

Ao pensar sobre essa conceituação, não temos dúvidas quanto à escolha das mulheres do Moinhos em envolverem-se com o esporte, e particularmente com o voleibol, de alguma maneira estar atravessada pelo descanso, pela diversão e desenvolvimento pessoal. No entanto, aquela prática não só servia ou era boa para repor energias após o trabalho, mas significava 0 envolvimento com uma rede de interação na qual o esporte - e inclusive o desgaste físico de cada jogo e treinamento ${ }^{9}$ - fazia sentido e estava acompanhado de compromissos, e também muito próximo das suas obrigações familiares.

Nos jogos da Liga não era incomum encontrar mulheres destinando parte do seu tempo para envolver-se na preparação de cada rodada do campeonato. Entre elas, destacavase 0 trabalho de Joana, pois ela assumia o cargo de Coordenadora Geral da Liga. Além das observações no decorrer do trabalho de campo, foi durante a entrevista que conseguimos retomar pontualmente 0 assunto sobre a lógica de trabalho que poderia estar envolvida em sua atividade:

7 Para compreender o desenvolvimento histórico do campo de estudos sobre o lazer poderiam ser consultados os trabalhos de Gomes (2003) e Gomes e Melo (2003).

8 Cabe ressaltar que o trabalho de Joffre Dumazedier (1976; 1979), cuja proposta inicial de pesquisa data dos anos 1950, foi de extrema importância para a construção de estudos e reflexões sistemáticas na área do lazer. Suas pesquisas ofereceram contornos e sustentaram debates sobre uma esfera da vida social que até então era colocada à margem dos debates acadêmicos.

9 Esse tema poderia ser discutido a partir de Elias e Dunning (1992), quando defendem que as atividades esportivas no lazer estão vinculadas não ao relaxamento, no sentido do descanso, mas à busca de um tipo de tensão agradável. Se fosse relaxação das tensões no sentido de descanso, dizem Elias e Dunning (1992, p. 141), "seria melhor ir para a cama do que ir [...] a um jogo de futebol". 
[Iniciamos a conversa dessa forma: "sempre te vejo bastante envolvida com a organização da Liga..."] É, mas não é um trabalho, é um prazer. É uma coisa que eu gosto. Estamos sempre assim conversando, contando história e isso ai me envolve, tô sempre conhecendo gente (JOANA, 2012).

A fala de Joana enfatiza que a Liga, de uma maneira geral, não assume o sentido de trabalho, mas não podemos deixar de considerar que ela se colocava na responsabilidade de organizar todas as rodadas e recorrentemente tomava determinadas decisões sobre a dinâmica dos campeonatos. Além disso, ela se responsabilizava pela contratação e pagamento da equipe de arbitragem e precisava "correr atrás" da premiação para as equipes vencedoras na etapa final. Assim como ela investia seu tempo na preparação dos finais de semana de jogos e na organização de sua própria equipe, era naquele espaço que ela também trabalhava com a comercialização de peças do vestuário feminino.

Assim como Joana sabia o que vender, ela havia construído uma rede de comercialização de seus produtos, pois não era incomum encontrar pessoas procurando-a para "olhar suas roupas". A elaboração dessa rede comercial informal não era um caso particular, pois no dia a dia dos ginásios encontrávamos pessoas vendendo cosméticos, roupas femininas, tênis, joelheiras e bolas de voleibol, material de treinamento - até sapatos de salto alto eram vendidos à beira da quadra, o que parecia não ter qualquer relação com o meio esportivo.

Podemos encontrar essas relações que borram a separação entre trabalho e lazer na pesquisa de Myskiw, Mariante Neto e Stigger (2010). Esses autores mostraram que no circuito de futebol de várzea da cidade de Porto Alegre/RS os "trabalhadores da várzea" eram os conhecedores do contexto e, portanto, sabiam como exercer suas atividades da maneira mais lucrativa, ocupavam os espaços do campo e, especialmente, o seu entorno para obter e/ ou reforçar sua renda familiar. Além da equipe de arbitragem, estavam envolvidos com a várzea os vendedores, fotógrafos, catadores de material reciclável, jornalistas e freteiros, todos que realizavam suas atividades profissionais e organizavam seu comércio, assim como viviam o futebol e faziam parte de um espaço/tempo reconhecido como um ambiente de lazer.

Também no carnaval encontramos situações como as relatadas acima. Em trabalho sobre a Cidade do Samba no Rio de Janeiro/RJ, Blass (2008) percebeu que o ambiente carnavalesco era capaz de agregar a vivência dos foliões que pulavam o carnaval ao mesmo tempo em que eram eles os próprios trabalhadores a construir cenários, fantasias e um mercado de consumo e atividades profissionais que também eram significativos para a continuidade daquele espaço/tempo de lazer.

Foi a partir dessas situações que passamos a problematizar uma determinada "lógica de obrigações" que pauta conceitos que se propõem a delimitar o que deveria fazer parte somente do trabalho e que, por outro lado, coloca o lazer como outra categoria distante dessas mesmas "obrigações". Essa definição polarizada acaba por enrijecer o próprio conceito e 0 torna distante do cotidiano das pessoas que fizeram parte dos trabalhos discutidos neste texto.

Através da relação entre essas pesquisas, procuramos mostrar que as fronteiras entre trabalho e lazer e, principalmente, a oposição entre essas duas dimensões, podem se dissolver conforme cada contexto. No entanto, mesmo que as distinções tornem-se imprecisas e/ou passem a conviver na lógica de determinadas dinâmicas sociais, os espaços e tempos permanecem sendo reconhecidos como "de lazer". Além disso, observamos que a distinção entre contextos a partir de uma ideia de "obrigações" também se dissolve quando falamos das relações familiares. 
Ao frequentar os ginásios onde aconteciam as competições da Liga, não era incomum encontrar crianças que, enquanto inventavam suas brincadeiras nas arquibancadas, assistiam suas mães participando dos jogos. Embora houvesse uma normativa ${ }^{10}$ que buscava evitar a presença de crianças dentro do espaço de jogo, era frequente a presença de alguns(mas) filhos(as) das jogadoras caminhando em volta das quadras. Abaixo, descrevemos uma dessas situações:

[Sábado de etapa do campeonato] A demora em retornar de um pedido de tempo chama a atenção. Com exceção de uma jogadora, todas as outras já estavam em suas posições. Ao procurar a mulher que 'faltava em quadra', acabei encontrando-a na tarefa de trocar a roupa de sua filha que estava em pé, em cima do banco de reservas, na lateral da quadra. Rapidamente, ela mudou a blusa da menina, arrumou seu casaco e somente quando terminou de aprontá-la, retornou para o jogo. Não escutei nenhum comentário quanto a essa situação, seja por parte de outras jogadoras, técnico ou qualquer posicionamento da arbitragem ao que seria uma situação de punição devido ao retardo na continuação da partida (DC, 30 abr. 2011).

Por intermédio desse excerto procuramos mostrar que as obrigações familiares (envolvidas com o fato de ajudar a filha a trocar-se) e as exigências que faziam parte do esporte (a mãe/jogadora precisava retornar à quadra), conviviam no cenário da Liga. Essa situação era semelhante ao que acontecia com Duda, uma das jogadoras do Moinhos que levava seu filho para todos os campeonatos. Nesses dois casos não foi identificado qualquer impedimento ou desavença da parte dos demais participantes (jogadoras, árbitros, organizadores). Além disso, não era incomum perceber essas mulheres planejando suas atividades familiares de acordo com a tabela do campeonato e, assim, ajustavam "suas vidas" com os compromissos da Liga.

Buscando o debate com Dumazedier e pautada pela ideia de complexidade das dinâmicas sociais, Gomes (2004a) também critica essas formulações e coloca que as polarizações deixaram de fazer sentido na atualidade, mas sem apresentar dados empíricos. Procurando nos distanciar de afirmações que constroem essas polarizações/generalizações, nos dedicamos a olhar para o que as pessoas fazem e, especialmente, como a fronteira do "tempo de lazer", construída teoricamente em relação às "obrigações", não dá conta de compreender essas práticas cotidianas significadas como "de lazer".

Oferecendo outras pistas para compreender o lazer, Marcellino (2002; 2008) buscou uma relação entre estas subdivisões da vida social e apresentou uma compreensão do lazer vinculada à combinação de dois aspectos: um deles relacionado ao "tempo" e o outro ligado à "atitude". A primeira definição estaria encarregada de delimitar aspectos sobre o tempo em que as pessoas se envolvem com suas práticas, que poderia ser considerado como um "tempo disponível" de obrigações, especialmente no que se refere ao trabalho. A outra noção estaria ligada à "atitude" dos sujeitos frente às atividades que escolhem para esse "tempo disponível". A partir dessas noções, Marcellino passa a definir o lazer como:

A cultura - compreendida no seu sentido mais amplo - vivenciada (praticada ou fruída) no 'tempo disponível'. O importante, como traço definidor, é o caráter 'desinteressado' dessa vivência. Não se busca, pelo menos fundamentalmente, outra recompensa além da satisfação provocada pela situação (MARCELLINO, 2002, p. 31).

Considerando os limites deste texto, não nos detivemos na própria discussão sobre o conceito de cultura, mas cabe fazer a ressalva de que essa pesquisa etnográfica esteve alicerçada em uma noção semiótica de cultura, cuja proposta entrelaça a dinâmica social a uma

10 Decidida em reunião entre as equipes. 
rede de significações que é formada pelos indivíduos e que estes também se formam a partir dessa mesma rede (GEERTZ, 1989). Nesse sentido, passamos a compreender o lazer como uma dentre as diversas dimensões da vida, inserido em uma rede de referenciais simbólicos, os quais são formados e formadores dos sujeitos que atuam nesses contextos. Essa noção é diferente de entender a cultura "no seu sentido mais amplo" (MARCELLINO, 2002, p.31), sendo essa uma expressão que nos parece pouco esclarecedora, pois desconsidera a compreensão de comportamentos, símbolos, instituições e processos cotidianos particulares aos diferentes tempo/espaços de lazer.

Ao conviver sistematicamente com a equipe, percebemos também que "o lazer daquelas mulheres" operava com "misturas" e "disputas" "de" e "por" tempos, os quais estavam distante da ideia de "disponibilidade" que está presente na definição de Marcellino (2002). Em várias situações, a noção de tempo extrapolava e se fazia simultânea com esferas, contextos, situações e as participantes da Liga sabiam negociar escolhas com a família, trabalho, folgas, compromissos, inclusive com "outras demandas" no âmbito do lazer. Sendo assim, as diferenças entre "obrigações" do trabalho e com a família não definia aquele lazer a priori, mas elas engendravam aquele espaço/tempo em que as jogadoras "viviam" o voleibol.

No decorrer desse primeiro tópico nos dedicamos a problematizar definições de lazer, pautadas em polarizações, que acabam definindo-o (teoricamente) e deixando-o distante do dia a dia das pessoas comuns, como se fosse um tempo/espaço entre parênteses. Além de dialogar com esses referenciais, nos propomos, assim, a considerar o lazer como algo que é "bom para pensar" (MAGNANI, 2000, p.23) a própria dinâmica da vida social, especialmente a partir da convivência com aquele grupo de mulheres que parecia colocar o lazer entre as negociações cotidianas que borram fronteiras entre diferentes dimensões da experiência cotidiana.

$\mathrm{Na}$ sequência, retomaremos uma noção de "atitude", também basilar para a compreensão de lazer e ligada à satisfação, à liberdade de escolha, ao descompromisso e aos ideais lúdicos aparentemente "desinteressados".

\section{E QUANDO O INTERESSE ESTÁ TAMBÉM NA SERIEDADE?}

Nas ações ou atitudes das pessoas que pertenciam à equipe havia certa liberdade na escolha por aquele espaço/tempo e uma vivência do esporte relacionado à brincadeira, ao divertimento e, em certa medida, nas suas falas estava contida a ideia de que o voleibol era somente um pretexto para estar naquela rede de sociabilidade. Essas noções guardam uma determinada representação de lazer entrelaçada com uma concepção de lúdico ${ }^{11} \mathrm{e}$ de atitude em seu caráter individual de realização, satisfação, liberdade de escolha e - quem sabe - até uma postura crítica construtiva sobre a realidade (GAELZER, 1979; MARCELLINO, 2008).

No entanto, havia outras situações em que as ações tornavam-se distantes dessas representações que acabam delimitando - mesmo que teoricamente - o que deveria acontecer em espaços/tempos de lazer. Inicialmente, essas tensões foram percebidas na medida em que, para dar continuidade ao trabalho de campo, foi preciso estar "dentro de quadra" e reconhecer que para manter-se no Moinhos era preciso "render em quadra" e/ou saber "estar fora dela".

11 Nessa pesquisa não nos detivemos em aprofundar o debate sobre o conceito de lúdico/ludicidade. Referimo-nos a essa noção corrente entre os estudos do lazer a partir de uma ideia de fruição das emoções entrelaçada com maneiras de "brincar consigo, com o outro e com 0 contexto" (GOMES, 2004b, p.145) de forma "não séria" e pautando-se em concepções de liberdade, diversão e relaxamento. 
Nesse sentido, havia uma noção de seriedade ligada à produtividade que convivia com o caráter lúdico naquele contexto. O rendimento esportivo entrava como mediador de participações na equipe, pois não só definia a permanência da pesquisadora em campo, como também circulava recorrentemente entre as avaliações de quem convidar para jogar. Tornavase, então, uma referência significativa para identificar "boas jogadoras" para o Moinhos. Geralmente, essa ideia de quem "tem nível" estava articulada com um "saber jogar" reconhecido no cenário do voleibol e, particularmente, ao saber jogar na Liga.

O que identificamos como "saber jogar" apareceu com clareza durante a entrevista de Rafaela. Enquanto conversávamos sobre um possível perfil de jogadora para o Moinhos, perguntei quem ela convidaria para fazer parte da equipe. Sendo sucinta em sua resposta, afirmou que: "Em primeiro lugar que fosse legal e que jogasse bem, eu não convidaria alguém que não jogasse bem, porque eu quero ganhar, me frustra perder sempre" (RAFAELA, 2012).

Embora o resultado das partidas assumisse diferentes significados dentro da equipe, a noção sobre o rendimento esportivo também atravessava a fala das mulheres que pertenciam ao grupo há mais de uma década, especialmente quando se referiam a quem convidar para jogar no Moinhos. Durante uma conversa, Vivi encerrou o assunto sobre o convite a ser feito a uma nova integrante, estabelecendo uma relação entre a possível aceitação dessa candidata e a sua capacidade de rendimento relacionado ao voleibol. Embora Vivi constatasse que 0 quorum estava diminuindo a cada treino, considerava que "tem que ver se vale a pena mesmo" (DC, 15/03/2012). Assim, esse "saber fazer", reconhecido como "adequado" à participação na equipe, não somente mediava os convites, mas também permeava as avaliações sobre a continuidade com o grupo. Trazemos um excerto para auxiliar nesse debate:

Na saída do treino, quando já estávamos na rua, em frente ao ginásio, fiquei perto de Sandra e Ellen. Enquanto elas conversavam sobre a discussão ocorrida durante o treino, vejo Marta, que já estava saindo do estacionamento, parar 0 carro e deslocar-se até onde nos encontrávamos. Os desentendimentos do treino fizeram com que as duas voltassem a conversar. Sandra, que estava visivelmente irritada com o desempenho esportivo de Marta, perguntou a ela: "você acha que tem condições físicas e emocionais de estar aqui? Eu não estou tendo mais" (DC, 14 abr. 2011).

Esse diálogo nos mostrou que a ideia de pertencimento era atravessada também por questões relacionadas ao desempenho "dentro de quadra" e, além disso, estava na pauta de discussões cotidianas do grupo. Além disso, percebemos que a seriedade com a qual o rendimento esportivo era tratado acabou definindo, inclusive, a saída de uma das mulheres da equipe, situação que descrevemos no trecho do diário de campo abaixo:

[Durante uma discussão no final do treino] Ana falou que: "Só pode vir jogar quem tem nível, não pode ser qualquer um para aceitar a vir jogar aqui. A partir de agora não entra mais ninguém, não dá para ficar se preocupando com essas coisas, já temos muitos problemas" [se referindo às lesões de algumas jogadoras que diminuíam o quorum para os treinamentos]. Enquanto todas falavam ao mesmo tempo, trocando opiniões sobre o que estava acontecendo [a saída de uma jogadora], ouço Leila comentar: "eu avisei que isso iria acontecer, decidimos pedir para ela se retirar e ninguém falou, agora deu nisso. Não dá! Ela atrapalha o treino". [...] No carro, indo para um restaurante, ela continuou a conversa com a seguinte afirmativa: "é lazer, tudo bem, mas é sério, tem um objetivo competitivo, todo mundo ali foi atleta, a sua maneira, mas foi" (DC, 16 nov.2010). 
Assim como era preciso "saber jogar" de acordo com o que era estabelecido na equipe, também era necessário "saber jogar na Liga". Esse segundo "saber", construído em reciprocidade com o primeiro, foi percebido a partir do momento em que uma nova jogadora entrou na equipe, a Duda, e depois de alguns jogos afirmou que: "Eu não consigo me soltar, não sei jogar assim" (DC, 24 set.2011). Meses depois, em uma conversa após um jogo, Duda comentou: "Eu preciso que alguém me irrite dentro da quadra, não consigo jogar nessa calmaria" (DC, 11 dez. /2011).

Essas falas de Duda nos ensinaram que naquele contexto existia um "saber" que não estava somente relacionado ao voleibol, mas era um saber específico que "estava em jogo" exigindo determinada produtividade e delimitando também as participações. Após os primeiros treinos de Duda, eram recorrentes as falas referentes às suas ações enquanto jogadora da equipe: "Ela é muito engraçada, muito louca", "Ela é pilhada mesmo", "Gente! Ela é muito louca".

No dia a dia do grupo, algumas estratégias eram construídas para que as ações e os comportamentos, em jogo ou fora dele, permanecessem dentro daquilo que se esperava. Era recorrente a utilização da fala "boleira aqui não" em contraste ao "vamos jogar direito" ou "vamos jogar sério", pois, como ouvi em entrevista "quem não se adapta vai sair naturalmente ou o Moinhos vai tirar" (TAÍS, 2012, grifo nosso).

Em certa medida, essas discussões sobre o rendimento dentro de um "lazer esportivo" já vêm fazendo parte de algumas pesquisas que procuraram compreender o esporte como escolha e prática sistemática em campos, ginásios e praças no ambiente urbano. No trabalho de Stigger (1997) essa questão estava entre as análises do que o autor chamou de "movimento dos veteranos de futebol". Entre esses grupos de homens veteranos que se reuniam em torno do futebol, os que frequentavam o Parque Ararigbóia aos sábados pela manhã, a produtividade nos jogos e a importância dada aos resultados das partidas eram determinantes para a aceitação no grupo. Além disso, essas noções passavam a fazer parte das próprias características do grupo, que só aceitava jogadores que apresentassem uma produtividade no jogo capaz de ajudar o time a vencer as partidas. Nesse grupo do Ararigbóia, o momento da competição parecia demandar uma maior seriedade dentro de uma convivência que oscilava entre o sério e o não sério (STIGGER, 1997).

Esse olhar, centrado no jogo e na noção de rendimento esportivo, também estava no trabalho de Myskiw, Pacheco e Freitas (2011), no qual as discussões se referiam ao Campeonato de Verão da Liga do Ararigbóia - categoria Veteranos - na cidade de Alegre/ RS. Essa competição era reconhecida no contexto do futebol de várzea como um espaço de "bom futebol", que reunia bons jogadores e times de diferentes locais da cidade ou da Região Metropolitana. Naquele contexto "dizer que só é divertido se for levado a sério não é uma incoerência ou uma contradição, pelo contrário, corresponde às expectativas das pessoas envolvidas no Campeonato de Verão" (MYSKIW; PACHECO; FREITAS, 2011, p. 3).

Cabe aqui destacar que essa ideia de performance esportiva, de produtividade, de exigência "no" e/ou "do" lazer se torna uma contradição quando assumimos uma representação de lazer ligada somente ao seu caráter libertário, lúdico, descompromissado e que trata de maneira negativa qualquer forma de produtividade. Naquele grupo de mulheres, "jogar sério" e "jogar bem" estava entre os assuntos mais divertidos, assim como a convivência e as risadas "dentro" e "fora" da quadra. 
No decorrer do texto passamos a colocar que para jogar no Moinhos era preciso ter um nível de voleibol condizente com o que a equipe esperava de cada jogadora. Essa questão dialoga com um conjunto de habilidades, conhecimentos e experiências específico para circular e assumir um lugar nesse contexto ${ }^{12}$. Embora essa noção fosse significativa para compreender como essas mulheres viviam o esporte, a seriedade não estava centrada somente nessas noções que envolviam as formas de jogar.

A seriedade no lazer atravessava também os compromissos que cada uma das mulheres assumia com o grupo. Para entrar no Moinhos era preciso estar ciente de que, um sábado por mês, a equipe participaria das rodadas na Liga e que toda semana haveria treinamentos nos quais seria preciso "suar a camiseta". Destacamos que as ausências eram permitidas, mas seria preciso encontrar uma justificativa reconhecida pelo grupo que, por sua vez, geralmente, insistia numa negociação. Essa ideia dos compromissos com o grupo fazia parte da lógica de funcionamento dos Caídos na Praia, um grupo de praticantes de futebol estudado por Stigger (2002). Mesmo que ali não houvesse exigência de rendimento esportivo, entre os integrantes dos Caídos, era necessário assumir um compromisso com o grupo, no qual a assiduidade nas rotinas e horários dos jogos de domingo era um critério com peso especial para incorporação de um novo membro ou identificação de um "bom integrante".

Assim como assumir o compromisso era algo valorizado na lógica da equipe, a noção de seriedade também atravessava os investimentos dessas mulheres com o grupo. Para jogar na Liga era preciso pagar a taxa de inscrição no campeonato, pois era exigida uma arbitragem "qualificada", ginásios em "boas condições" e materiais de jogo chancelados pela CBV. Dentro da equipe eram negociados os investimentos financeiros em um treinador não somente reconhecido no cenário do voleibol, mas, particularmente, reconhecido entre as lideranças do grupo.

Além dessas questões financeiras, fazer parte do Moinhos exigia certa dedicação e investimento corporal na atividade. Não era incomum encontrar as dores no corpo também fazendo parte dos treinamentos e jogos: Ana contou que "jogava somente à base de remédio" (DC, 14 out. 2010); os treinos na segunda após as etapas de campeonato estavam, de antemão, cancelados, pois elas "precisavam recuperar o corpo" (DC, 02 maio 2011); durante uma viagem, Roberta, em um tom de brincadeira, expôs que "hoje só deveria jogar quem não tem dor. Bom, então ninguém vai jogar!" (DC, 10 dez.2011). Esses são alguns exemplos a partir dos quais é possível pensar que o dispêndio corporal estava entrelaçado com a seriedade de envolverse com aquela forma de viver o esporte. A equipe sabia lidar com a ausência de alguma jogadora que estava no "departamento médico", as mulheres sabiam conviver com suas dores, conheciam seus limites, e transcendê-los fazia parte de suas escolhas para aquele lazer.

A partir desses diferentes compromissos, exigências e investimentos, procuramos trazer ao debate diferentes questões que fazem parte da seriedade no lazer de um grupo de mulheres. Envolver-se com o lazer e, em particular, com o esporte dessa forma, parece ser um dos caminhos para manter um nível de tensão e excitação que permeia as escolhas por determinados espaços e tempos. Essas noções são consideradas por Elias e Dunning (1992, p.143) como um "denominador comum" entre as práticas significadas como de lazer, embora elas diferenciem-se umas das outras, pois, em cada contexto, haverá um nível de tensãoexcitação particular. Segundo os autores, essas atividades representam uma esfera da vida

12 Pacheco (2012) dialoga essas noções com o trabalho de Stebbins (2008). Este autor desenvolve uma formulação teórica chamada de Perspectiva do Lazer Sério, cuja proposta é identificar diferentes formas de vivenciar o lazer, especialmente aquelas que exigem habilidades especiais, conhecimento e experiência. 
que mais ofereceria às pessoas a possibilidade de experimentarem uma agradável estimulação das emoções e "uma divertida excitação que pode ser experimentada em público, partilhada com outros e desfrutada com aprovação social e boa consciência" (ELIAS; DUNNING, 1992, p.151).

A seriedade parecia fazer sentido para aquelas mulheres. No entanto, essa afirmação naquele contexto se tornava distante de uma ideia de produtividade que "oprime", de um rendimento esportivo que desconsidera a capacidade de manejo dessa própria noção pelas pessoas ou do compromisso que colocaria em risco o caráter libertário do lazer. Assim como "jogar bem" e "jogar com quem joga bem" fazia parte da agradável estimulação das emoções, o comprometimento com o grupo e os investimentos naquela maneira de viver o esporte também atravessavam a procura por níveis ótimos de tensão e excitação e não poderiam ser compreendidos como parte de um "ato desinteressado".

Além dessas análises, podemos olhar para os "atos" a partir da perspectiva de Pierre Bourdieu. Na esteira dos debates desse autor, somos levados a considerar que as ações dos agentes sociais estão inseridas e - ao mesmo tempo - são frutos de um jogo social. Portanto, não são desinteressadas, mas estão ligadas a determinadas disposições incorporadas pelos indivíduos no "seu" espaço social (BOURDIEU, 2005). Essa discussão mereceria uma maior profundidade que não cabe nos limites e objetivos deste texto, mas ressaltamos que as ações e sentidos que fazem parte dos espaços e tempos de lazer não são desconectados de outras esferas da vida social ou possuem um fim em si mesmos. Ao contrário, eles se tornam parte de uma dinâmica complexa do cotidiano que permite diferentes adjetivações (sério, lúdico, produtivo, eficaz, livre) na composição de um mesmo espaço e tempo de lazer.

\section{CONSIDERAÇÕES FINAIS}

A trajetória dessa etnografia foi marcada pela construção e dissolução de inúmeras perguntas, dentre as quais o lazer foi ganhando destaque. No decorrer do trabalho, procuramos estabelecer debates entre o que as pessoas faziam nos seus espaços e tempos de lazer (particularmente nos que envolviam a prática do esporte) com os conceitos que nos ofereciam contornos - e limites - sobre esse mesmo tema. Esse diálogo estava engendrado aos questionamentos da pesquisa que gravitaram em torno de compreender como aquele grupo se sustentava ao longo dos anos e como isso se articulava com o fato de se manterem pertencentes à Liga. Além disso, nos interessamos em saber como elas se mantinham engajadas naquele espaço/tempo reconhecido como "um lazer que era levado a sério".

Neste trabalho procuramos retirar a compreensão do lazer de um lugar "entre parênteses" que, por vezes, o coloca em outro polo ou o desconecta de noções que caracterizariam a particularidade da dimensão do trabalho ou das responsabilidades familiares. No ano de 1979, Lenea Gaelzer já trazia autores que apontavam que "não existe entre o jogo e o trabalho uma fronteira absoluta" (MARINHO, 1956 apud GAELZER, 1979, p.51) e foi nessa linha que passamos a pensar o lazer, não mais procurando contornos e diferenças entre "obrigações" de determinadas esferas (também construídas teoricamente), mas compreendendo-o como um espaço/tempo formado pelas pessoas que, ao mesmo tempo, se formam a partir dele.

Foi por pautar-nos com essa maneira de compreender a própria pesquisa (num constante ir e vir de reflexões com as pessoas e ouvindo o que elas têm a nos ensinar sobre 0 
"seu lazer") que essa dimensão da vida pode ser percebida na sua diversidade. Nesse contexto, a produtividade, o rendimento esportivo, a seriedade, os compromissos, os interesses e os investimentos entraram em cena e foram relativizados. Isto não aconteceu para que essas noções fossem colocadas no lugar da brincadeira, do descompromisso, da diversão, do desenvolvimento, de uma concepção de lúdico, mas, sim, porque nelas encontramos pistas de como as pessoas vivenciam algo que por elas é significado como "lazer" e que nos ajudaram a dialogar com algumas conceituações "do lazer" que permeiam essa área de estudos.

\section{REFERÊNCIAS}

BLASS, Leila Maria da Silva. Rompendo Fronteiras: a Cidade do Samba no Rio de Janeiro. Revista Brasileira de Ciências Sociais, São Paulo, v.23, n.66, p.79-205, fev. 2008.

BOURDIEU, Pierre. É possível um ato desinteressado? In: BOURDIEU, Pierre. Razões Práticas: sobre a teoria da ação. 6. ed. Campinas: Papirus, 2005. p.137-156.

GAELZER, Lenea. Lazer: benção ou maldição? Porto Alegre: SULINA/UFRGS, 1979.

OLIVEIRA, Roberto Cardoso. O trabalho do antropólogo: olhar, ouvir, escrever. In: OLIVEIRA, Roberto Cardoso. (org.). 0 trabalho do antropólogo. 2. ed. Brasília: Paralelo 15; São Paulo: UNESP, 2006. p. 17.

DUMAZEDIER, Joffre. Lazer e cultura popular. São Paulo: Perspectiva, 1976.

DUMAZEDIER, Joffre. Sociologia Empírica do Lazer. São Paulo: Perspectiva, 1979.

ELIAS, Norbert; DUNNING, Eric. A busca da excitação. Lisboa: Difel, 1992.

FONSECA, Cláudia Lee Williams. Quando cada caso NÃO é um caso: pesquisa etnográfica e educação. Revista Brasileira de Educação, São Paulo, n.10, p.58-78, jan/abril, 1999.

FOOTE-WHYTE, William. Treinando a observação participante. In: GUIMARÃES, Alba Zaluar. (org.). Desvendando máscaras sociais. Rio de Janeiro: Francisco Alves, 1980. p. 77.

CAMARGO, Luiz Octávio de Lima. 0 que é Lazer. São Paulo: Brasiliense, 1989.

GEERTZ. Clifford. A interpretação das culturas. Rio de Janeiro: Jorge Zahar, 1989.

GOMES, Christianne Luce. Significados de recreação e lazer no Brasil: reflexões a partir da análise de experiências institucionais (1926-1964). 2003. 322f. Tese (Doutorado) - Programa de PósGraduação em Educação, UFMG, Belo Horizonte, 2003.

GOMES, Christianne Luce; MELO, Victor Andrade. Lazer no Brasil: trajetória de estudos, possibilidades de pesquisa. Movimento, Porto Alegre, v. 9, n. 1, p. 23-44, jan./abr. 2003.

GOMES, Christianne Luce. Lazer - concepções. In: GOMES, Christianne Luce. (org.). Dicionário Crítico do Lazer. Belo Horizonte: Autêntica, 2004a. p.119.

GOMES, Christianne Luce. Lúdico. In: GOMES, Christianne Luce. (org.). Dicionário Crítico do Lazer. Belo Horizonte: Autêntica, 2004b. p.141.

MAGNANI, José Guilherme Cantor. Lazer, um campo interdisciplinar de pesquisa. In: BRUHNS, Heloisa Turini; GUTIERREZ, Gustavo Luis. (orgs.). 0 corpo e o Lúdico: ciclo de debates lazer e motricidade. Campinas: Autores Associados, 2000. p.19.

MAGNANI, José Guilherme Cantor. Etnografia como prática e experiência. Horizontes Antropológicos, Porto Alegre, v.15, n.32, p.129-156, jul./dez. 2009.

MARCELLINO, Nelson Carvalho. Estudos do Lazer: uma introdução. 3. ed. Campinas: Autores Associados, 2002. 
MARCELLINO, Nelson Carvalho. Lazer e educação. 13. ed. Campinas: Papirus, 2008.

MYSKIW, Mauro; MARIANTE NETO, Flávio Py; STIGGER, Marco Paulo. Trabalhadores da Várzea: notas etnográficas sobre apropriação dos espaços de lazer para o trabalho. In: CONGRESSO BRASILEIRO DE CIÊNCIAS DO ESPORTE, 2010, Itajaí. Anais... Itajaí, 2010. p.1.

MYSKIW, Mauro; PACHECO, Ariane Corrêa; FREITAS, Maitê Venuto. "Jogo pegado, é assim que tem que ser": estudo sobre a seriedade do lazer numa rede de sociabilidade masculina. In: CONGRESSO BRASILEIRO DE CIÊNCIAS DO ESPORTE, 2011, Porto Alegre. Anais... Porto Alegre, 2011. p.1.

PACHECO, Ariane Corrêa. "É lazer, tudo bem, mas é sério": o cotidiano de uma equipe máster feminina de voleibol. 2012. 128 f. Dissertação (Mestrado) - Programa de Pós-Graduação em Ciências do Movimento Humano, UFRGS, Porto Alegre, 2012.

STEBBINS, Robert Alan. Serious Leisure: a perspective for our time. New Jersey: Transaction, 2008.

STIGGER, Marco Paulo. Futebol de Veteranos: um estudo etnográfico sobre o esporte no cotidiano urbano. Movimento. Porto Alegre, v. 4, n.7, p. 52-66, 1997.

STIGGER, Marco Paulo. Esporte, lazer e estilos de vida: um estudo etnográfico. Campinas: Autores Associados, 2002.

STIGGER, Marco Paulo. Lazer, Cultura e Educação: possíveis articulações. Revista Brasileira de Ciências do Esporte. Campinas, v. 30, n. 2, p. 73-88, jan. 2009.

WINKIN, Yves. Descer ao campo. In: WINKIN, Yves. A nova comunicação: da teoria ao trabalho de campo. Campinas: Papirus, 1998. p.129. 
Apoio financeiro: Coordenação de Aperfeiçoamento de Pessoal de Nível Superior (CAPES)

(J) Movimento, Porto Alegre, v. 22, n. 1, 129-142, jan./mar. de 2016. 